\title{
Proposta de redução de tempo de setup em máquinas de testes de durabilidade em uma empresa fornecedora de autopeças com o uso de conceitos SMED e padronização
}

Lucas Verzenhassi Toledo lucasverzenhassi@yahoo.com.br
Faculdades Integradas Einstein de Limeira (FIEL), Limeira, São Paulo, Brasil

\section{Matheus de Moraes}

matheusmoraes1993@hotmail.com

Faculdades Integradas Einstein de Limeira (FIEL), Limeira, São Paulo, Brasil

\section{Ivan Correr}

icorrer@yahoo.com.br

Faculdades Integradas Einstein de Limeira (FIEL), Limeira, São Paulo, Brasil

\begin{abstract}
RESUMO
Devido à concorrência atual, as organizações perseguem incansavelmente a otimização dos processos, com a eliminação de desperdícios, redução de custos, aumento de produtividade e qualidade através de conceitos como: Lean Manufacturing, que visa reduzir os desperdícios; Conceitos do SMED, que visa à diminuição do tempo de setup; e Padronização, que visa normalizar, esquematizar e metodizar atividades. Neste contexto, o presente artigo visa apresentar uma proposta de melhoria para redução do tempo de setup das máquinas de testes de durabilidade em uma empresa fornecedora de autopeças, baseando-se nos conceitos da ferramenta SMED e métodos de padronização das atividades de setup. Para isso, foi utilizada a metodologia da pesquisa-ação, construindo hipóteses, coletando e analisando dados para a resolução do problema em estudo. Estima-se uma redução de $55 \%$ do tempo médio das operações de setup e maior confiabilidade no processo com a padronização das atividades, evidenciando a importância dos conceitos propostos.
\end{abstract}

PALAVRAS-CHAVE: Setup. SMED. Padronização. 


\section{INTRODUÇÃO}

No cenário atual, com o aumento da competitividade, as organizações buscam aumentar a produtividade, diminuir custos, diminuir o ciclo de produção, atender as flutuações de demanda do mercado e introduzir novos produtos com agilidade. Através da manufatura enxuta ou Lean Manufacturing, é possível obter vantagens competitivas, com o máximo uso dos recursos disponíveis, produzindo diversos produtos com qualidade e lead time baixo, oferecendo flexibilidade e maior força para a competição mercadológica (CONCEIÇÃO et al., 2009).

Uma das atividades que auxiliam o aumento da competitividade em função da redução do tempo de preparação do processo é sistema SMED (Single Minute Exchange of Dye) ou TRF (Troca Rápida de Ferramentas) proposto por Shingo (1985).

Conforme Palomino e Lucato (2016), o SMED mostra-se eficaz, com a ampliação da lucratividade, qualidade e produtividade. A redução de desperdícios e a diminuição do tempo da operação de Setup é fundamental para as organizações obterem competitividade e flexibilidade no cenário atual. Os resultados da implementação do SMED são alcançados por meio da padronização dos processos, com baixo investimento e retorno expressivo para a organização.

Em relação à padronização de processos, Campos (2013) define que esta é a base das atividades diárias e deve direcionar os meios (métodos) e os fins (metas e objetivos) para execução das atividades, e Costa et al. (2016) apresenta que a padronização reduz vários tipos de desperdícios, aumenta a quantidade de itens produzidos com qualidade e também possibilita maior domínio do processo produtivo.

A padronização de processos oferece suporte e melhoria contínua às execuções de atividades agregadoras de valor, baseadas em normalizações, esquematizações, sistematizações e vários métodos que controlam e adequam os resultados, desde que as orientações sejam claras e objetivas para a execução de cada tarefa (CAVANHA FILHO, 2006; TAYLOR, 2010).

Neste contexto, o presente artigo tem como objetivo apresentar uma proposta de melhoria para redução de tempo de Setup das máquinas de testes de durabilidade de uma empresa fornecedora de peças automotivas, baseandose nos conceitos da ferramenta SMED com o uso de métodos de padronização de processos.

\section{REFERENCIAL TEÓRICO}

\section{LEAN MANUFACTURING}

O sistema de produção conhecido por Manufatura Enxuta ou Lean Manufacturing é um conjunto de ações, princípios e ferramentas que, quando aplicadas, visam a eliminação das causas raízes de baixa performance.

Iniciada na década de 1950 por dois japoneses chamados Eiji Toyoda e Taiichi Ohno, a Manufatura Enxuta também está contida no Sistema Toyota de Produção (TPS) (SUGAI; MCINTOSH; NOVASKI, 2007). 
Para Shingo (1996), o princípio fundamental do TPS é a eliminação de desperdícios e estes são classificados em sete tipos, conforme abaixo (OHNO, 1997; RODRIGUES, 2014):

- Desperdícios por superprodução: produção em quantidades maiores que o necessário ou produzidas no momento errado, gerando estoques;

- Desperdícios por espera: Tempo de máquinas e mão-de-obra ociosa pelo processo ou por material;

- Desperdícios por transportes: Movimentações desnecessárias de peças, estoques, equipamentos, geralmente causado por layouts mal planejados;

- Desperdícios por processamentos: Superdimensionamento do processo ou tarefas desnecessárias;

- Desperdícios por estoques: Produtos acabados, semiacabados e matériaprima com grandes volumes estocados no processo desnecessariamente;

- Desperdícios por movimentos desnecessários: Movimentação dos operadores na realização das atividades do processo seja essa ocorrida por maquinário, layout e/ou ergonomia ineficientes;

- Desperdícios por produtos defeituosos: Produtos em não conformidade com as especificações, podendo provocar retrabalho ou o descarte dos mesmos.

O Lean Manufacturing proporciona diversos benefícios para as organizações, focando na melhoria contínua através da redução dos desperdícios. As aplicações das ferramentas do Lean são eficazes com o trabalho padronizado já implementado, pois quando não há padronização, as melhorias não se perpetuam (VIEIRA et al., 2016).

Conforme Paiva e Bergiante (2016), o Lean Manufacturing é um pilar estratégico da empresa, pois essa ferramenta contribui para a sustentabilidade financeira.

O Lean Manufacturing possui diversas características, que podem ser verificadas a seguir (DUARTE et al., 2015):

- Estratégia de aumento de produtividade;

- Identificação das atividades que agregam valor e também a cadeia de valor de todo processo;

- Redução das quantidades de perdas de matéria-prima;

- Redução de custos de manutenção e;

- Proporciona padrões de qualidade.

Duarte et al. (2015) e Conceição et al. (2009), citam benefícios sucedidos do Lean Manufacturing e que estão descritos em seguida:

- Redução de desperdícios;

- Redução esforços necessários;

- Produzir grande família de produtos;

- Lead time baixo;

- Utilização eficiente dos recursos disponíveis; 
- Aumento produtividade;

- Aumento qualidade;

- Diminuição de retrabalhos e;

- Flexibilização da manutenção.

Para visualização e definição das causas raízes, podem ser efetuados o diagrama de Ishikawa e os cinco porquês. Algumas ações podem ser tomadas para que os desperdícios anteriormente citados possam ser minimizados ou ainda eliminados e, exemplos dessas ações estão na união de maquinários de um mesmo processo a fim de eliminar transportes, utilização de lotes únicos de produção - One Piece Flow - com a finalidade de eliminar estoques em processo e também esperas, minimização de tempos de ciclos dos processos produtivos, adoção de inspeções diretamente na fonte para que sejam evitados processamentos de produtos defeituosos, implantação da ferramenta SMED, a fim de diminuir tempos de repostas com a diminuição dos tempos de Setup, dentre outros (SHINGO, 1996; LIKER, 2005; CARVALHO, 2010).

\section{SMED}

Setup é definido por Hirano (2009), como todas as preparações que devem ser feitas antes de um conjunto de operações serem iniciadas, ou seja, todas as etapas de preparações, parametrizações, montagens, referenciamentos, medições, correções, dentre outras diversas operações a serem realizadas antes de que o processo produtivo seja iniciado.

Os conceitos básicos do sistema SMED (Single Minute Exchange of Dye) ou TRF (Troca Rápida de Ferramentas) proposto por Shigeo Shingo (1985) em seus estudos é o de todo e qualquer setup seja realizado em tempos com somente um dígito, ou seja, tempos inferiores a 10 minutos. Para isso, é necessário que as operações de preparação sejam divididas e classificadas em etapas internas ou externas à máquina, conforme publicado pelo mesmo autor no ano de 2000.

Shingo (2000) propõe em sua metodologia, com a finalidade de melhorar o processo de preparação dos maquinários, em um estágio preliminar, onde deve se analisar e aferir as condições atuais do processo de setup. Em uma etapa posterior, devem-se separar os processos internos que são os que somente podem ser realizados com a máquina parada, dos processos externos que, contrariamente aos internos, podem ser realizados com a máquina em operação.

Ainda para o mesmo autor, a etapa subsequente consiste em transformar os processos de preparação internos em processos externos, pois assim, evita-se deixar a máquina ociosa para realização de processos de preparação e que não acrescentam valores ao produto final. A última etapa da implantação da metodologia SMED, consiste na etapa de melhoria contínua dos processos preparatórios visando sempre a redução dos tempos de setup e, consecutivamente, aumentando a disponibilidade do maquinário para novos setups e para a produção de outros produtos que se façam necessários.

O SMED é efetivo em reduzir o tempo de preparação e, assim, permite efetuar maiores quantidade de setups por obter maior disponibilidade e possibilidade de diversificações de produtos com pequenos lotes, com menores 
lead times, aumento da produtividade, maior obtenção de lucros e maior agilidade na resposta ao cliente (BASTOS; LOFFAGEN; CARDOSO, 2016; DIAS et al., 2016).

A técnica do SMED permite que os envolvidos possuam maior entendimento de todo o processo de preparação separando, compactando e transferindo atividades em internas ou externas, obtendo redução de tempo ocioso e proporcionando maior competitividade para as organizações (SILVA; ALSISI; COSTA, 2016; REIS; ALVES, 2010).

Com a aplicação do SMED, é possível realizar padronizações das atividades que não são de extrema criticidade ao processo, porém que também são fundamentais para a confiabilidade da qualidade do produto por meio de inspeções e maior agilidade na troca de produtos (GAZEL; SALLES; FEITOSA, 2014).

\section{PADRONIZAÇÃO}

De acordo com Cavanha Filho (2006), a padronização oferece suporte e melhoria contínua às execuções de atividades em operações agregadoras de valor, baseadas em normalizações, esquematizações, sistematizações e vários métodos que controlam e adequam os resultados.

Conforme Taylor (2010) é necessário detalhar o trabalho que será executado. Com a finalidade de instruir o executante da tarefa, podem ser utilizadas documentações escritas, desde que as orientações sejam claras e objetivas para a execução de cada tarefa.

A padronização é a base das atividades diárias e deve direcionar os meios (métodos) e os fins (metas e objetivos) para execução das atividades (CAMPOS, 2013).

A padronização reduz vários tipos de desperdícios, aumenta a quantidade de itens produzidos com qualidade e também possibilita a obtenção de maior domínio do processo produtivo (COSTA et al., 2016).

Conforme Ramon et al. (2016), a padronização motiva melhorias contínuas nas tarefas executadas. Devido à falta de padronização, não há visibilidade do processo de execução das tarefas, por consequência, obtém-se maior dificuldade em resolver os problemas na causa raiz e, consecutivamente, o faturamento pode ser reduzido.

A padronização dos processos diminui perdas as do tempo de produção e de produtos, contribui para a redução de desperdícios e aumenta a qualidade da produção. Para implementar a padronização, o investimento é mínimo, sendo necessário apenas realizar diversos ajustes no processo em análise (IONAK, 2016).

A padronização tem como objetivo diminuir as variações relacionadas às atividades e, assim, é possível reduzir o tempo da atividade e otimizar os movimentos necessários para sua realização (CAVANHA FILHO, 2006).

Campos (2013) cita ferramentas de apoio para padronizar o ambiente de trabalho, sendo elas: 
Fluxograma: Utilização do fluxograma com intuito de aumentar e maximizar a produtividade e qualidade, sendo que em todos os níveis da organização sejam estabelecidos quais os processos que estão sob responsabilidade de cada indivíduo ou departamento. O fluxograma também auxilia na confecção do mapeamento dos processos, evidenciando diversos processos. Também é importante que o fluxograma retrate a situação verdadeira do local;

Definição de tarefas com prioridades: Determinar junto à equipe, quais são as atividades principais nas quais se deve focar para realizar as padronizações;

Procedimentos operacionais padronizados: São procedimentos de operações e não do processo. É necessário que todos os operadores efetuem as atividades da mesma maneira e no mesmo fluxo.

Também podem ser citadas, as instruções de trabalho que contribuem para que os colaboradores sejam adequadamente treinados e também para que possuam autonomia e segurança nas atividades, possibilitando a padronização (VIEIRA et al., 2016).

De acordo com Santanna et al. (2016), a falta de padronização é prejudicial nas organizações, pois causa produtos finais caros, obtenção de barreiras para aprendizados e a agilidade de disponibilidade do produto e de tomada de ações são reduzidas. Para que a padronização seja realizada, é possível utilizar ferramentas da qualidade, entre elas:

- Fluxogramas;

- Diagramas;

$-5 \mathrm{~W} 2 \mathrm{H}$ e;

- 5 por quês.

A implementação da padronização nos processos proporciona melhor qualificação e maior satisfação no trabalho para os colaboradores, gera estabilidade no processo e como consequência, diminui os níveis de refugo, controlando os custos relacionados a produtividade. Nota-se também que, para o sucesso da implementação da padronização, todos os funcionários devem estar motivados e a alta administração deve fornecer apoio para a implantação (TEIXEIRA, 2014).

\section{METODOLOGIA DO DESENVOLVIMENTO DA PESQUISA}

O artigo refere-se a uma pesquisa ação, que é definido por Thiollent (2009) e Trip (2005) como a pesquisa sobre ações de problemas ou resoluções de problemas, onde o grupo de pesquisadores estão envolvidos diretamente à situação, sendo de modo participativo ou cooperativo. A pesquisa ação possui diversas, características, conforme Quadro 1 a seguir (GILBERTONI, et al., 2016): 
Quadro 1- Principais características da pesquisa ação

\begin{tabular}{|c|c|}
\hline Características & Descrição \\
\hline Pesquisa e ação & $\begin{array}{c}\text { Contribuir para o conhecimento científico } \\
\text { Solucionar problemas e promover melhorias nas } \\
\text { organizações }\end{array}$ \\
\hline Teoria e prática & $\begin{array}{c}\text { Ambas devem ser conduzidas simultaneamente } \\
\text { A teoria suporta as práticas produzidas }\end{array}$ \\
\hline pesquisadores & $\begin{array}{c}\text { Trabalham efetivamente para a resolução do } \\
\text { problema }\end{array}$ \\
& $\begin{array}{c}\text { Facilita o dialogo e promove analises entre os } \\
\text { participantes }\end{array}$ \\
\hline Processo cíclico & $\begin{array}{c}\text { Ciclo de auto-reflexão } \\
\text { Diagnósticos das situações }\end{array}$ \\
& \begin{tabular}{c} 
Planos de ação Escrita dos resultados finais \\
\hline
\end{tabular} \\
\hline
\end{tabular}

Fonte: Adaptado de Gilbertoni, et al. (2016)

O delineamento do presente trabalho foi adotado conforme Gil (2010) e Mello et al. (2012), destacado a seguir:

- Fase exploratória: Tem como objetivo determinar o ambiente de investigação, as expectativas e os auxílios que os interessados podem oferecer ao decorrer da pesquisa;

- Formulação do problema: Visa garantir a definição do problema com precisão;

- Construção de hipóteses: As hipóteses devem ser claras, sucinta, sem ambiguidade gramatical e que possibilita realizar verificações empíricas;

- Realização do seminário: Reúne os membros da equipe de pesquisadores e interessados no desenvolvimento da pesquisa, nessa etapa, a discussão e a aprovação nos seminários são as diretrizes da pesquisa-ação;

-Seleção da amostra: Após a limitação da pesquisa, é necessário determinar elementos que serão pesquisados sendo que, amostras intencionais são mais relevantes para os pesquisadores e participantes, sendo a mais adequada para a pesquisa-ação;

- Coleta de dados: A técnica aplicada para a coleta de dados são as observações dos pesquisadores e participantes;

- Análise e interpretação dos dados: A análise de dados deve ser realizada pelos pesquisadores e participantes, por meio dessa abordagem colaborativa, a análise dos participantes é fundamental, pois eles que convivem com aquele ambiente todos os dias;

- Elaboração plano de ação: Após a análise, deve ser elaborado um documentado de plano de ação, onde deve incluir os objetivos, quais tipos de mudanças necessárias, quais medidas e procedimentos podem contribuir com a situação, e também, determinar o controle e avaliação dos resultados; 
- Divulgação de resultados: Os resultados podem ser expostos em simpósios, relatórios, conferências, dentre outros.

\section{PESQUISA-AÇÃO}

Esse trabalho tem como local de estudo um laboratório de testes experimentais de uma grande empresa localizada na cidade de Limeira, Estado de São Paulo. Neste laboratório, são testadas caixas de direção de veículos leves e pesados, sistemas de frenagem e também sistemas de segurança aos ocupantes, porém o foco inicial será dado ao departamento de testes de caixas de direção de veículos leves.

Os testes em caixas de direção do tipo pinhão-cremalheira - Rack and Pinionaplicadas à veículos leves, podem ser classificados como testes funcionais, estruturais, de durabilidade, dentre outros e podem ocorrer na validação de protótipos de novos produtos, validações/avaliações de novos fornecedores de componentes internos ou externos dos mecanismos de direção, testes periódicos chamados de Layout Inspection que visam a avaliação de características funcionais e estruturais de produtos em produção corrente e os testes também podem ocorrer de acordo com solicitações e demandas dos setores produtivos ou de engenharia.

Todos os testes realizados no laboratório seguem criteriosamente normas internas, coorporativas ou ainda normas de grandes montadoras de veículos que são clientes da empresa em estudo e, por se tratar de um produto que está diretamente ligado com a segurança e conforto dos ocupantes do veículo, os testes experimentais são de suma importância para a verificação e validação do funcionamento dos mecanismos de direção e, consecutivamente, do veículo final no qual será instalado.

Os testes de durabilidade ocorrem em máquinas de grande tecnologia embarcada e que contam com controladores, servo-válvulas, atuadores lineares e rotacionais. Esses testes possuem por finalidade a simulação de condições mais severas do que as quais os veículos estão sujeitos durante toda a vida útil deste automóvel.

Esses testes de durabilidade ocorrem, conforme anteriormente citado, em acordo com normas e especificações e no fluxograma abaixo (Figura 1), pode-se visualizar a sequência lógica e simplificada destes testes.

Figura 1 - Fluxograma dos testes

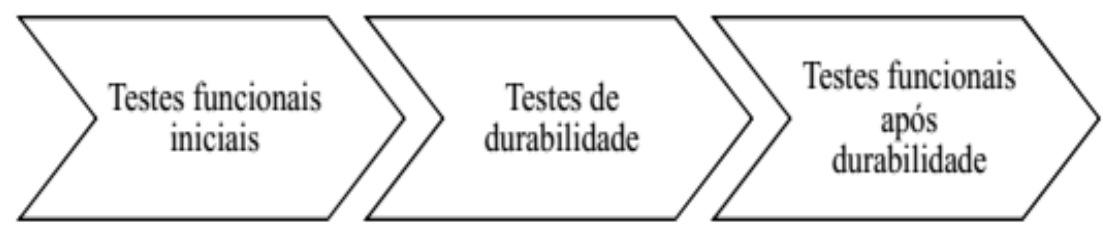

Fonte: Os autores

A fixação dos mecanismos de direção às máquinas de durabilidade ocorre de acordo com orientações veiculares e normativas, ou seja, os testes devem ser realizados com as caixas de direção fixadas de forma que sejam gerados ângulos 
iguais aos quando instalados no veículo de aplicação para qual tenha sido desenhado e projetado e, para tal correta fixação, são necessárias bases e dispositivos também desenvolvidos, avaliados e validados para o projeto. Essas bases são compostas por 04 componentes que são a base inferior, coluna, base superior de fixação e ainda por inserto e, a composição desses elementos irá resultar em uma altura final de fixação, sendo essa altura, fator determinante nos ângulos resultantes de fixação, conforme podemos observar na Figura 2.

Figura 2 - Fixação da caixa de direção na máquina de testes

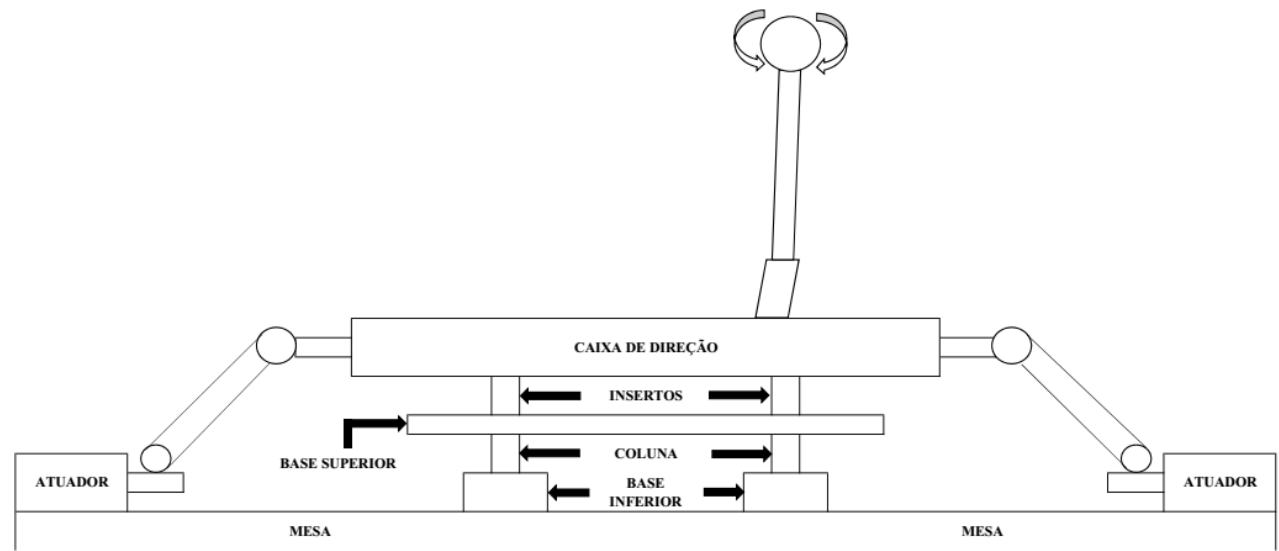

Fonte: Os autores

Conforme citado anteriormente, as alturas das bases de fixação dos mecanismos às máquinas de durabilidade são de suma importância e, devido à grande diversidade de produtos oferecidos e testados no laboratório, existem diversas composições e montagens possíveis de dispositivos de fixação, gerando em alguns casos, retrabalhos, desperdícios de tempo com medição e/ou seleção dos corretos componentes para montagem dos dispositivos, dentre outros. O tempo atual de execução de setups é de até aproximadamente 09 horas, devido à grande complexidade e exigência de detalhes e, também, muitas das vezes à montagem, medição e seleção dos componentes dos dispositivos e também, devido aos grandes números de retrabalhos executados.

Para a verificação dos motivos do tempo despendido na operação de setup, foi realizado entre os colaboradores do laboratório e o grupo de pesquisadores um diagrama de causa e efeito, onde foi abordada as possíveis causas raízes para o efeito, conforme pode ser observado na Figura 3. 
Figura 3 - Causa e efeito para a operação de setup

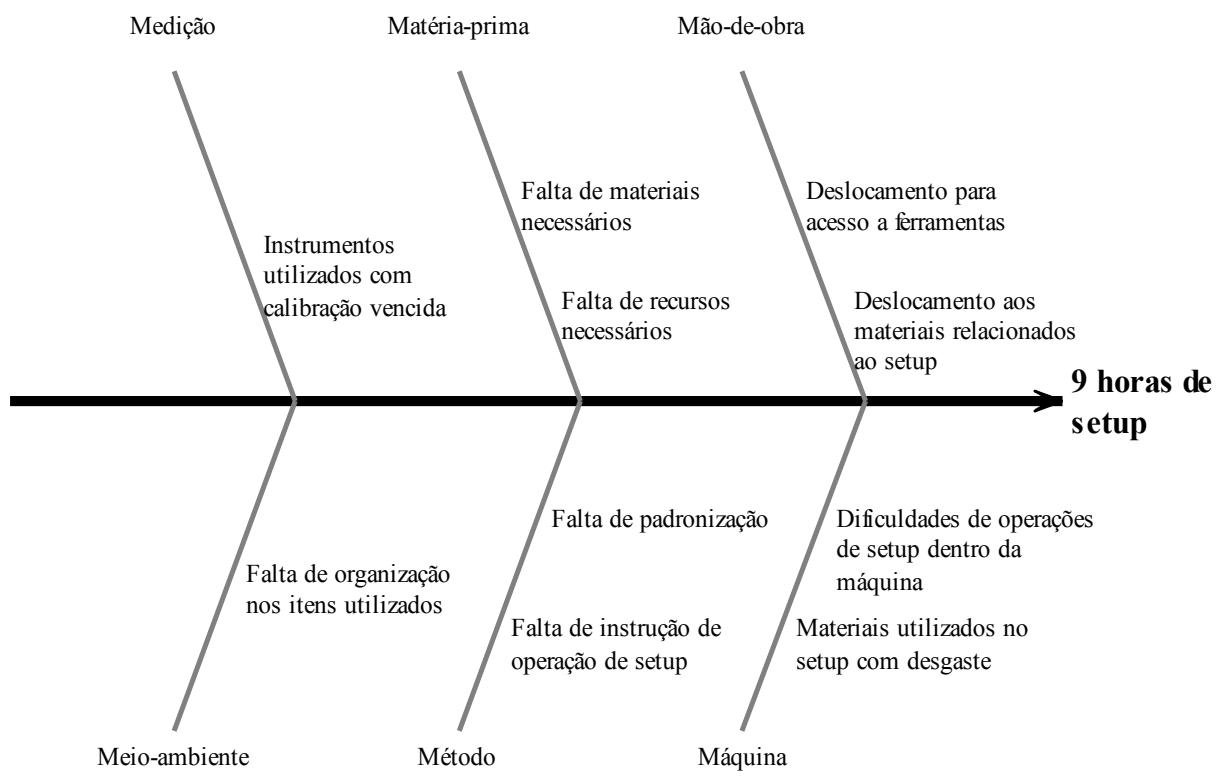

Fonte: Os autores

Após o diagrama de causa e efeito ser efetuado, foram discutidas as causas levantadas através de um seminário, e foram alcançadas as seguintes descrições, conforme abaixo:

- Medição: Os instrumentos de medição utilizados na operação de setup possuem calibração validada, ou seja, os valores estão conforme especificação e a calibração está validada e no prazo correto;

- Matéria-prima: Os materiais necessários para efetuar a troca das bases estão disponíveis para uso;

- Meio ambiente: Os materiais necessitam de uma organização e identificação mais adequada;

- Mão-de-obra: Deslocamento desnecessário por retrabalhos da operação de setup,

- Máquina: O setup realizado internamente é dificultoso, sendo que, a montagem é realizada passo a passo;

- Método: Não há padronização de métodos entre os colaboradores do setor por falta de procedimento ou instrução de trabalho.

Sendo assim, foi definido que, as diretrizes de análise, baseadas nos conceitos SMED e padronização, seriam:

- Verificar a possibilidade de transformar setup interno em externo;

- Melhorar a codificação e organização dos materiais;

- Propor instrução de trabalho, com o intuito de padronizar a operação, apresentando quais são os itens utilizados na operação e também como deve ser feita a atividade de setup, com a intenção de reduzir os retrabalhos utilizados. 
Com a definição das amostras, foi possível levantar os dados das operações com as observações dos pesquisadores e dos participantes, sendo assim, verificou-se no dia-a-dia as atividades da operação e realizou-se as medições de tempo dessas atividades e, através das medições efetuadas, foi possível apresentar o tempo médio das operações de setup com os retrabalhos efetuados (Figura 4) e também um fluxograma do estado atual (Figura 5) das operações de setup.

Figura 4 - Tempo médio das atividades do setup com retrabalho (estado atual)

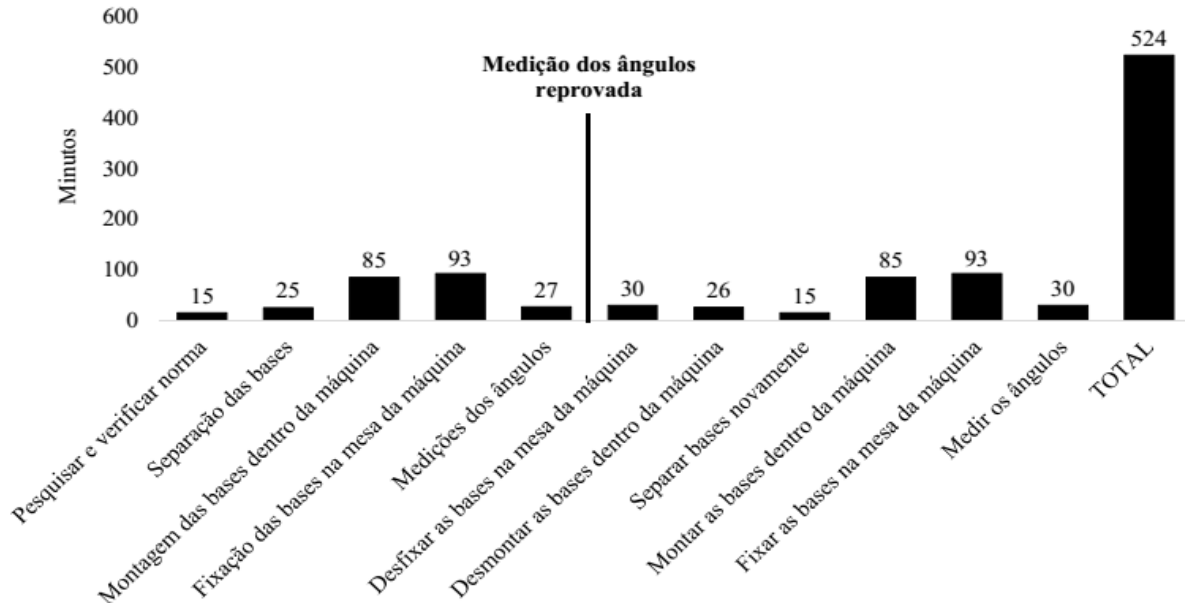

Fonte: Os autores

Uma vez que, ao ser citado no diagrama de causa e efeito (Figura 3), uma das possíveis causas da longa demora ao se efetuar os setups foi a falta de organização dos itens utilizados, especialmente os componentes das bases utilizadas para a fixação das caixas de direção e com a proposta de padronização abaixo citada, foi detectada a necessidade de identificação de todos os itens das bases, sejam eles colunas, insertos, bases inferiores ou superiores, e também um correto e lógico armazenamento desses componentes no armário no qual são guardados esses itens que não estão sendo utilizados para testes. 
Figura 5 - Fluxograma da operação de setup das máquinas de durabilidade (estado atual)

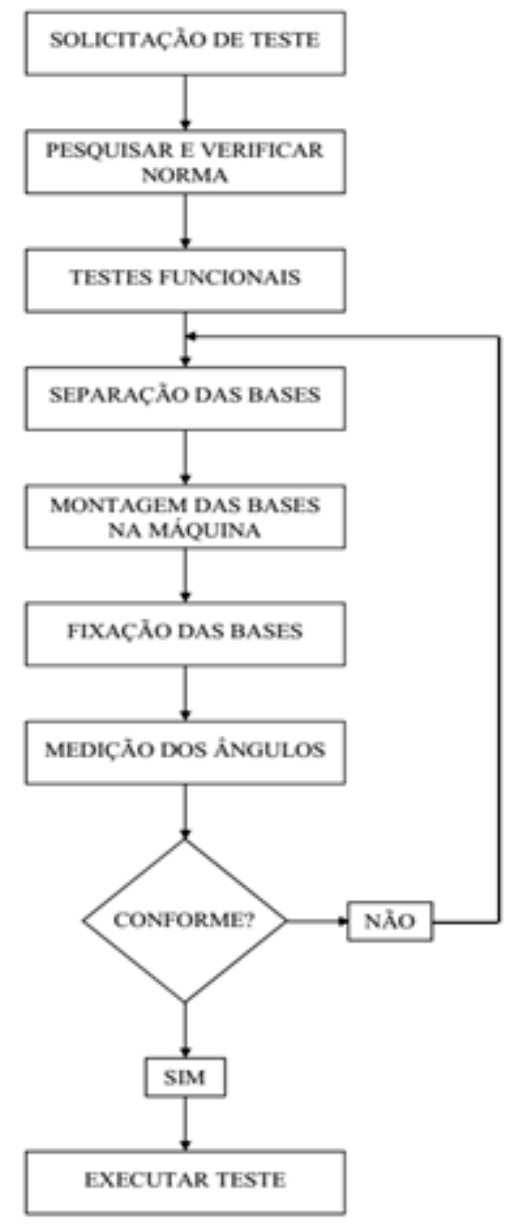

Fonte: Os autores

Essa identificação deverá ser realizada utilizando-se de ferramentas punção para escrita em aço e, nessa identificação, deve estar contido o número do dispositivo juntamente com sua medida de altura, para os insertos e colunas. Já a armazenagem desses itens no armário, deverá ser realizada de forma que sejam mantidos os itens de mesma codificação juntos (pares ou jogos) e também de forma em que os comprimentos dos insertos e colunas estejam em ordem crescente.

Com a identificação dos possíveis pontos de melhorias e também do maiores desperdícios durante o processo de preparação das máquinas de durabilidade, foi possível realizar a proposta de implementação de instruções de trabalho padronizadas, contendo as informações e itens necessários para a montagem das bases de testes, visando a extinção dos retrabalhos das montagens, conforme pode ser visto na descrição das atividades da operação setup (Quadro 2) e também nas folhas de verificações, conforme Figura 6, Figura 7 e Figura 8. 
Quadro 2: Instrução da operação setup

\begin{tabular}{|c|c|}
\hline $\begin{array}{c}\mathbf{N} \\
\text { Atividade }\end{array}$ & Atividades Executadas \\
\hline 1 & Verificar solicitação e normas de testes; \\
\hline 2 & Verificar na IT quais serão os materiais utilizados; \\
\hline 3 & Separar os materiais de acordo com a IT; \\
\hline 4 & $\begin{array}{l}\text { Posicionar as colunas sobre as bases inferiores, de modo que os furos } \\
\text { fiquem centralizados; }\end{array}$ \\
\hline 5 & Fixar os 03 parafusos de cada coluna as bases inferiores; \\
\hline 6 & $\begin{array}{l}\text { Posicionar os insertos centralizados nos alojamentos da base superior, } \\
\text { destinados ao mecanismo a ser testado; }\end{array}$ \\
\hline 7 & Fixar os insertos na base superior, sendo 03 parafusos M8 por inserto; \\
\hline 8 & $\begin{array}{l}\text { Posicionar a base superior sobre a coluna, de modo que os furos fiquem } \\
\text { centralizados; }\end{array}$ \\
\hline 9 & Fixar a base superior nas colunas, sendo 03 parafusos M10 por coluna; \\
\hline 10 & $\begin{array}{l}\text { Fixar a caixa de direção aos insertos, sendo um parafuso M12 para cada } \\
\text { inserto; }\end{array}$ \\
\hline 11 & $\begin{array}{l}\text { Transportar o conjunto pré-montado até a máquina, posicionando } \\
\text { centralizadamente a furação da base inferior aos furos da mesa; }\end{array}$ \\
\hline 12 & Fixar as bases inferiores na mesa com 04 parafusos 5/8"; \\
\hline 13 & $\begin{array}{l}\text { Fixar os outers aos atuadores e células de carga, utilizando os parafusos } \\
\qquad \text { dos outers e porcas } \mathrm{M} 12\end{array}$ \\
\hline 14 & $\begin{array}{l}\text { Fixar os inners a célula de carga, obedecendo as medidas descritas de } \\
\text { sobra de rosca especificadas na IT; }\end{array}$ \\
\hline 15 & $\begin{array}{l}\text { Fixar os inners ao mecanismo, aplicando o torque de aperto } \\
\text { especificado em norma. }\end{array}$ \\
\hline
\end{tabular}

Fonte: Os autores 
Figura 6 - Folha de verificação para montagem de máquina de testes de durabilidade XS 014

\begin{tabular}{|c|c|c|c|c|c|}
\hline \multirow{3}{*}{$\begin{array}{l}\text { Laboratório } \\
\text { Experimental }\end{array}$} & Produto: A & \multicolumn{4}{|c|}{ Máquina: (XS-014) } \\
\hline & \multicolumn{5}{|c|}{ Descrição do produto: A1 } \\
\hline & \multicolumn{5}{|c|}{ Descrição do teste: Durabilidade - Full Wear } \\
\hline & & \multicolumn{4}{|c|}{ Dimensões para Setup } \\
\hline & & \multicolumn{2}{|c|}{ Altura Total } & \multicolumn{2}{|r|}{-} \\
\hline & & \multicolumn{2}{|c|}{ Inserto } & \multicolumn{2}{|c|}{ DT-0910-04 $(80 \mathrm{~mm})$} \\
\hline & & \multicolumn{2}{|c|}{ Base Superior } & \multicolumn{2}{|c|}{ DT-0910-01 } \\
\hline & & \multicolumn{2}{|c|}{ Coluna } & \multicolumn{2}{|c|}{ DT-0910-03 (143mm) } \\
\hline & & \multicolumn{2}{|c|}{ Base Inferior } & \multicolumn{2}{|c|}{ DT-0910-01 } \\
\hline & & \multicolumn{2}{|c|}{ Altura Mesa } & \multicolumn{2}{|r|}{-} \\
\hline & & \multicolumn{2}{|c|}{ Conjunto LBJ } & \multicolumn{2}{|r|}{$\mathrm{X}+\mathrm{Y}$} \\
\hline \multirow{2}{*}{\multicolumn{2}{|c|}{$\begin{array}{c}\text { EPI's: } \\
\text { Óculos de proteção, Protetor auricular, Luva de malha. }\end{array}$}} & \multirow{2}{*}{\multicolumn{2}{|c|}{$\begin{array}{l}\text { Dimensões Inner } \\
\text { (sobra de rosca) }\end{array}$}} & \multirow{2}{*}{\multicolumn{2}{|c|}{$\begin{aligned} \text { Bush Side } & =16,4 \mathrm{~mm} \\
\text { Pinion Side } & =18,00 \mathrm{~mm}\end{aligned}$}} \\
\hline & & & & & \\
\hline & & Responsável & & tura & Data \\
\hline \multicolumn{3}{|c|}{ Elaborado: } & & & \\
\hline \multicolumn{3}{|c|}{ Revisado: } & & & \\
\hline \multicolumn{3}{|c|}{ Aprovado: } & & & \\
\hline
\end{tabular}

Fonte: Os autores

Figura 7 - Folha de verificação para montagem de máquina de testes de durabilidade XS 015

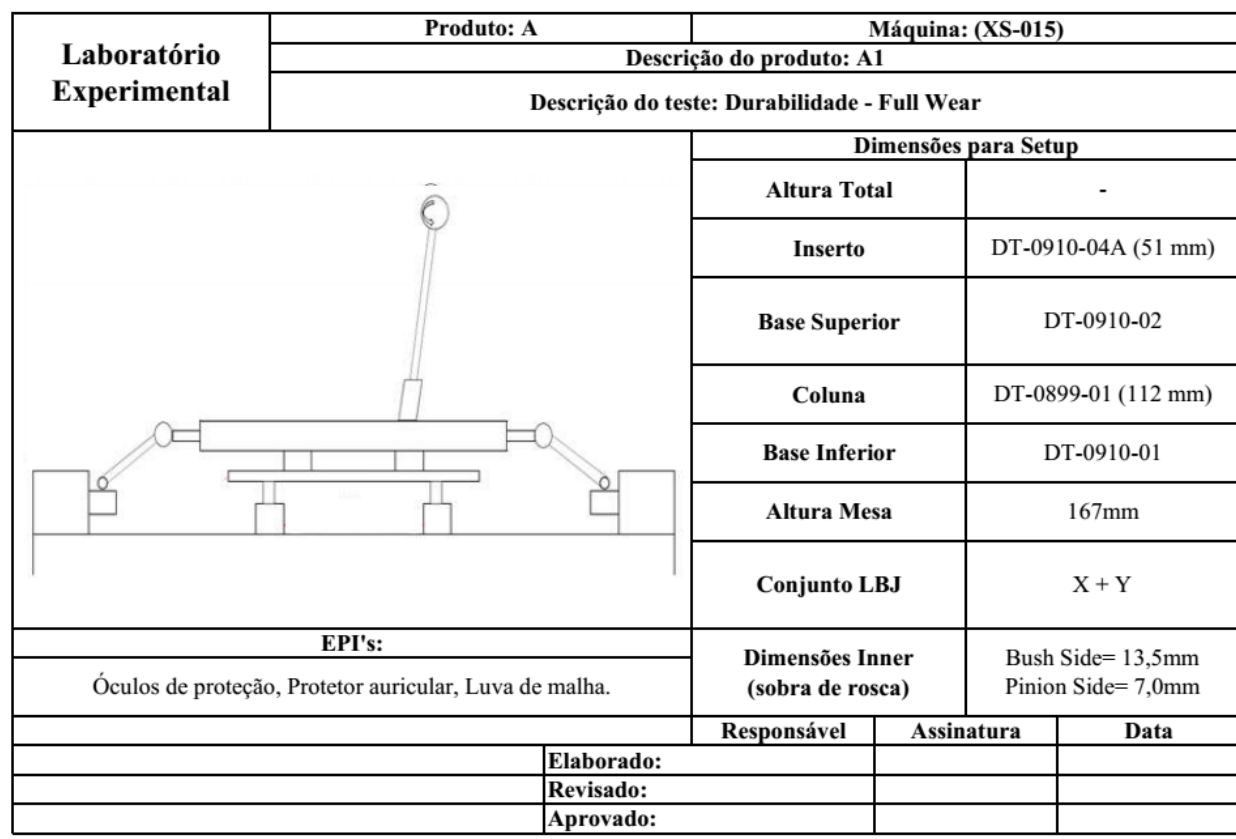

Fonte: Os autores 
Figura 8 - Folha de verificação para montagem de máquina de testes de durabilidade XS 023

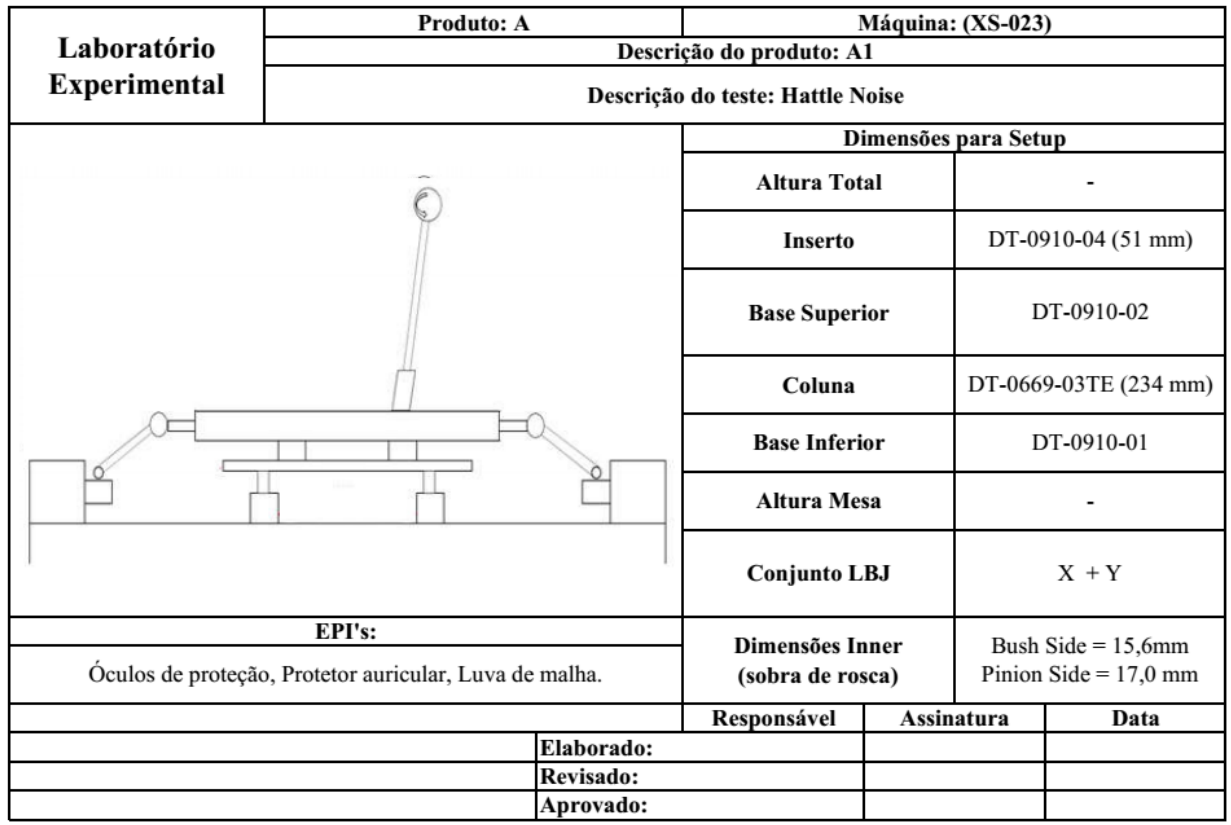

Fonte: Os autores

\section{ANÁLISE DOS RESULTADOS}

Com as propostas de melhorias apresentadas, espera-se que o tempo médio de preparação das máquinas de durabilidade passe de 524 minutos para 235 minutos, devido aos procedimentos, metodologia e padronização do processo de setup, atingindo assim, redução de aproximadamente 55\%, conforme apresentado na Figura 9 (Tempo médio de setup com as melhorias) e na Figura 10 (Fluxograma das atividades).

Figura 9 - Tempo médio das atividades do setup sem retrabalho (estado futuro)

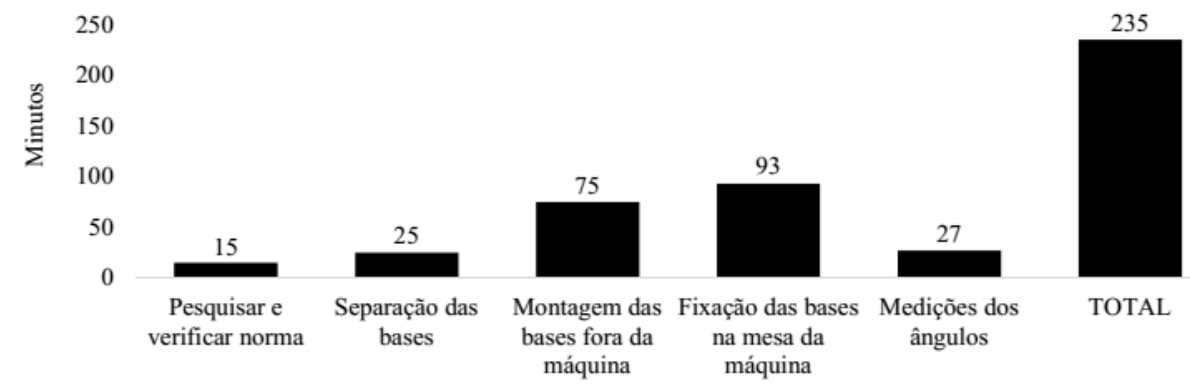

Fonte: Os autores 
Figura 10 - Fluxograma da atividade setup (estado futuro)

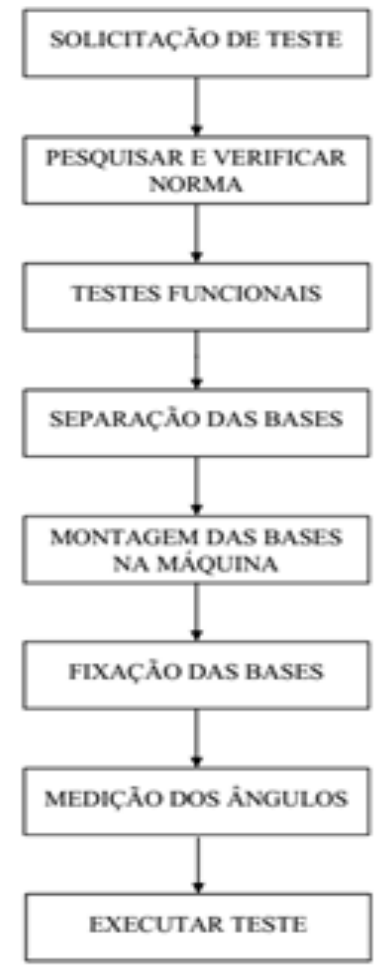

Fonte: Os autores

\section{CONSIDERAÇÕES FINAIS}

A pesquisa-ação desenvolvida teve como finalidade apresentar uma proposta de melhoria para redução do tempo de setup de máquinas de testes de durabilidade em uma empresa automotiva, utilizando como referência conceitos do SMED e também com o uso de conceitos da padronização de processos. Com isso, pôde-se concluir:

Com o uso dos conceitos SMED e da padronização, foi possível efetuar instruções de trabalho e folhas de verificações conforme pode ser observado no Quadro 6 e nas Figuras 6, 7 e 8;

- Com a utilização das instruções de trabalho e com as folhas de verificações, estima-se uma redução de $55 \%$ no tempo de setup conforme apresentado na Figura 9 e também um fluxo contínuo da execução da atividade, apresentado na Figura 10.

- Como consequência, outros benefícios não abordados no presente trabalho podem ser gerados, tais como:

- Reduções de custos com redução de atividades não agregadoras de valor;

- Maior agilidade e menores tempos de resposta às necessidades de resultados de testes;

- Maior disponibilidade da máquina para a realização de testes;

- Aumento de flexibilidade; 
- Maior conforto e confiança por parte dos funcionários do setor;

- Dentre outros benefícios.

Sugere-se para pesquisas futuras, o estudo de propostas de implementação para redução de desperdícios em laboratórios metalógrafos e em laboratórios de metrologia que utilizam dos mesmos conceitos operacionais e de testes da presente pesquisa. 


\title{
Proposal of setup time reduction in durability tests machines at an auto parts supplier using SMED and standardization concepts
}

\begin{abstract}
Due to current competition, organizations pursue tirelessly process optimization, with waste elimination, costs decreasing, productivity and quality increasing due to concepts as: Lean Manufacturing, which aims wastes reduction; Concepts of SMED, which aims setup time reduction; and Standardization, which aims standardize, schematize and methodize of activities. In this context, this article aims to present an improvement proposal of setup time reduction of durability tests machines, in an auto parts company, based on SMED concepts and standardization methods of setup activities. Thereunto, it was used research-action methodology, developing hypotheses, collecting and analyzing data's in order to solve the problem. It is estimated a decrease from $55 \%$ on average setup time and increase of process reliability with activities standardization, evidencing the importance of proposed concepts.
\end{abstract}

KEYWORDS: Setup. SMED. Standardization. 


\section{REFERÊNCIAS}

BASTOS, A. L. A. SMED e Redução do Tempo de Setup em um Processo Produtivo. In: VI Congresso Brasileiro de Engenharia de Produção. Anais... Paraná, 2016. p. 1-9.

CAMPOS, V. F. Gerenciamento da Rotina do Trabalho do Dia a Dia. 9 ed. Nova Lima: Falconi, 2013. 266p.

CARVALHO, M. T. Lean Manufacturing na Indústria de revestimentos de cortiça. Dissertação de Mestrado - Faculdade de Engenharia da Universidade do Porto, Portugal, 2010. 71p.

CAVANHA FILHO, A.O. Estratégia de Compras. Rio de Janeiro: Editora Ciência Moderna, 2006. 104p.

CONCEIÇÃO, S. V. et al. Desenvolvimento e implementação de uma metodologia para troca rápida de ferramentas em ambientes de manufatura contratada.

Revista Gestão e Produção, São Carlos. v. 16, n.3, p.357-369, jul-set. 2009. crossref

COSTA, L. E. A et al. Procedimento Operacional Padrão: Estudo de caso no setor de recebimento de peças importadas de uma empresa montadora de veículos. In: XXXVI Encontro Nacional de Engenharia de Produção. Anais... Paraíba, 2016. p. 113.

DIAS, E. N. et al. Troca Rápida de Ferramentas (TRF): análise da literatura para identificação de oportunidade de pesquisa. In: VI Congresso Brasileiro de Engenharia de Produção. Anais... Paraná, 2016. p. 1-12.

DUARTE, A. R. S et al. Aplicação do Lean Manufacturing no setor de manutenção de subconjuntos de uma mineradora de grande porte. In: XXXV Encontro Nacional de Engenharia de Produção. Anais... Ceará, 2015. p. 1-13.

GAZEL, W. F; SALLES, J. A. A; FEITOSA, W. H. Redução do tempo de Setup em uma linha de ingredientes sólidos de uma fábrica alimentícia do pim: Estudo de caso. In: XXXIV Encontro Nacional de Engenharia de Produção. Anais... Paraná, 2014. p. 15-26.

GIL, A. C. Como elaborar projetos de pesquisa. 5. ed. São Paulo: Atlas, 2010. $210 p$. 
GILBERTONI, D. et al. The contribution of action research in the construction of scientific knowledge in Brazilian Production Engineering. Revista Production. v.26, n.2, p. 373-384, abr./jun. 2016. crossref

HIRANO, H. JIT Implementation Manual: The Complete Guide to Just-In-Time Manufacturing. Volume 02, CRC Press: 2009 216p.

IONAK, R. M. Benefícios da implementação do Trabalho Padronizado na Águia Sistemas de Armazenagem S/A. In: VI CONGRESSO BRASILEIRO DE ENGENHARIA DE PRODUÇÃO. Anais... Paraná, 2016. p. 1-9.

LIKER, J. K. O modelo Toyota: 14 princípios de gestão da maior fabricante do mundo. Porto Alegre: Bookman, 2005. 320p.

MELLO, C. H. P. Pesquisa-ação na engenharia de produção: proposta de estruturação para sua condução. Revista Produção. Brasil. v.22, n.1, p.1-13, jan./fev. 2012.

OHNO, T. O sistema Toyota de Produção: Além da produção em larga escala. Tradução por Cristina Schumacher. Porto Alegre: Bookman, 1997. 152p.

PAIVA, N. T; BERGIANTE, N. C. R. Aplicação de conceitos enxutos na manufatura: A realidade Brasileira. In: XXXVI Encontro Nacional de Engenharia de Produção. Anais... Paraíba, 2016. p. 1-16.

PALOMINO, R.; LUCATO, A. V. R. Implementação da metodologia SMED: Um estudo de caso em uma célula de produção do ramo automobilístico. In: XXXVI Encontro Nacional de Engenharia de Produção. Anais... Paraíba, 2016. p. 1-26.

RAMON, C. R. et al. Padronização de Processos para Redução de Erros em uma Distribuidora: Um estudo de Caso. In: XXXVI Encontro Nacional de Engenharia de Produção. Anais... Paraíba, 2016. p. 1-15.

REIS, M. E. P.; ALVES, J. M. Um método para o cálculo do benefício econômico e definição da estratégia em trabalhos de redução do tempo de Setup. Revista Gestão e Produção. São Carlos. v.17, n.3, p.579-588, 2010.

RODRIGUES, M. V. Entendendo, aprendendo e desenvolvendo, Sistema de Produção Lean Manufacturing. Rio de Janeiro: Elsevier, 2014. 168p. 
SANTANNA, A. M. O. Modelo de Padronização de Processos em uma Industria de Termoformagem. In: XXXVI Encontro Nacional de Engenharia de Produção.

Anais... Paraíba, 2016. p. 1-13.

SHINGO, S. A Revolution in Manufacturing: The SMED System. Cambridge, MA: Productivity Press, 1985. 384p.

SHINGO, S. O Sistema Toyota de Produção: do ponto de vista da engenharia de produção. 2.ed. Porto Alegre: Bookman, 1996. 291p.

SHINGO, S. O Sistema de Troca Rápida de Ferramentas. Porto Alegre: Bookman Editora, 2000. 327p.

SILVA, J. P. N; ALSISI, R. B; COSTA, F. G. Aplicação da troca rápida de ferramentas em uma empresa de corte e dobra de aço. In: XXXVI Encontro Nacional de Engenharia de Produção. Anais... Paraíba, 2016. p. 1-13.

SUGAI, M.; MCINTOSH, R. I.; NOVASKI, O. Metodologia de Shigeo Shingo (SMED): análise crítica e estudo de caso. In: Revista Gestão e Produção. São Carlos. v. 14, n.2, p. 323-335, maio-ago. 2007.

TAYLOR, F. W. Princípios da Administração Científica. 8.ed. São Paulo: Atlas, 2010. $112 p$.

TEIXEIRA, P. C. et al. Padronização e melhoria de processos produtivos em empresas de panificação: estudo de múltiplos casos. In: Revista Production, v. 24, n.2, p. 311-321, Apr./June 2014.

THIOLLENT, M. Metodologia da pesquisa-ação. São Paulo: Cortez, 2009. 132p.

TRIP, D. Pesquisa-ação: uma introdução metodológica. In: Educação e Pesquisa. São Paulo, v.31, n.3, p. 443-466, Set./Dez. 2005. crossref

VIEIRA, E. L.; TRENTIN, G. M.; COSTA, S. E.G.; LIMA, E. P. Melhoria no layout de uma indústria metal mecânica utilizando ferramentas Lean Manufacturing. In: XXXVI ENCONTRO NACIONAL DE ENGENHARIA DE PRODUÇÃO. Anais... Paraíba, 2016. p. 1-21. 
Recebido: 20 nov. 2017

Aprovado: 23 mai. 2018

DOI: 10.3895/gi.v14n3.7373

Como citar:

TOLEDO, L. V; MORAES, M.; CORRER, I. Proposta de Redução de setup em máquinas de testes de durabilidade em uma empresa fornecedora de autopeças com o uso de conceitos SMED e padronização. $\mathbf{R}$. Gest. Industr., Ponta Grossa, v. 14, n. 3, p. 151-172, jul./set. 2018. Disponível em:

<https://periodicos.utfpr.edu.br/rgi>. Acesso em: XXX.

Correspondência:

Ivan Correr

Rua Ipiranga, 730, Apto. 151, Centro, Piracicaba, São Paulo, Brasil.

Direito autoral: Este artigo está licenciado sob os termos da Licença Creative Commons-Atribuição 4.0

Internacional. 